\title{
Chapter 4 \\ The Dwindling Role of Population Pressure in Land Use Change-a Case from the South West Pacific
}

\section{Torben Birch-Thomsen and Anette Reenberg}

Keywords Solomon Islands · Agricultural change - Coping strategies · Shifting cultivation $\cdot$ Rural livelihoods

\subsection{Introduction}

In this article, we will explore a contemporary coupled human-environmental system on a small island in the South West Pacific with the aim of portraying historical changes in the resource management strategies, notably the agricultural land use, in this former subsistence system.

Anthropologist and human-environment geographers have in various contexts considered such well-defined units as optimal laboratories for in-depth analyses of the dynamic complexities of human-environment systems (e.g. Fox et al. 2003; GLP 2005; Haberl et al. 2006; Lambin and Geist 2006; Scoones 1999; Walker et al. 2006; Zimmerer and Bassett 2003). Our reason for embarking on this study originated precisely in this tradition inasmuch as one of the classical human ecological studies from the 1960s has provided us with an excellent and very detailed set of baseline information about the land use-population-environment nexus approximately 50 years ago (Christiansen 1975). A recent opportunity to revisit and study the same environment using the same theoretical and conceptual mindset has provided us with unique material for a longitudinal analysis, which forms the backbone of the current chapter. Several sources of data were used including secondary data, a household survey, a population census, land use mapping based on remote sensing supported by ground truth, field walks and group interviews. The primary data were collected

T. Birch-Thomsen $(\square)$

Department of Geosciences and Natural Resource Management, Section of Geography, University of Copenhagen,

Øster Voldgade 10, 1350 København K, Denmark e-mail: tbt@ign.ku.dk
A. Reenberg
Department of Geosciences and Natural Resource Management,
Section of Geography, University of Copenhagen,
Øster Voldgade 10, 1350 København K, Denmark
e-mail: ar@ign.ku.dk 


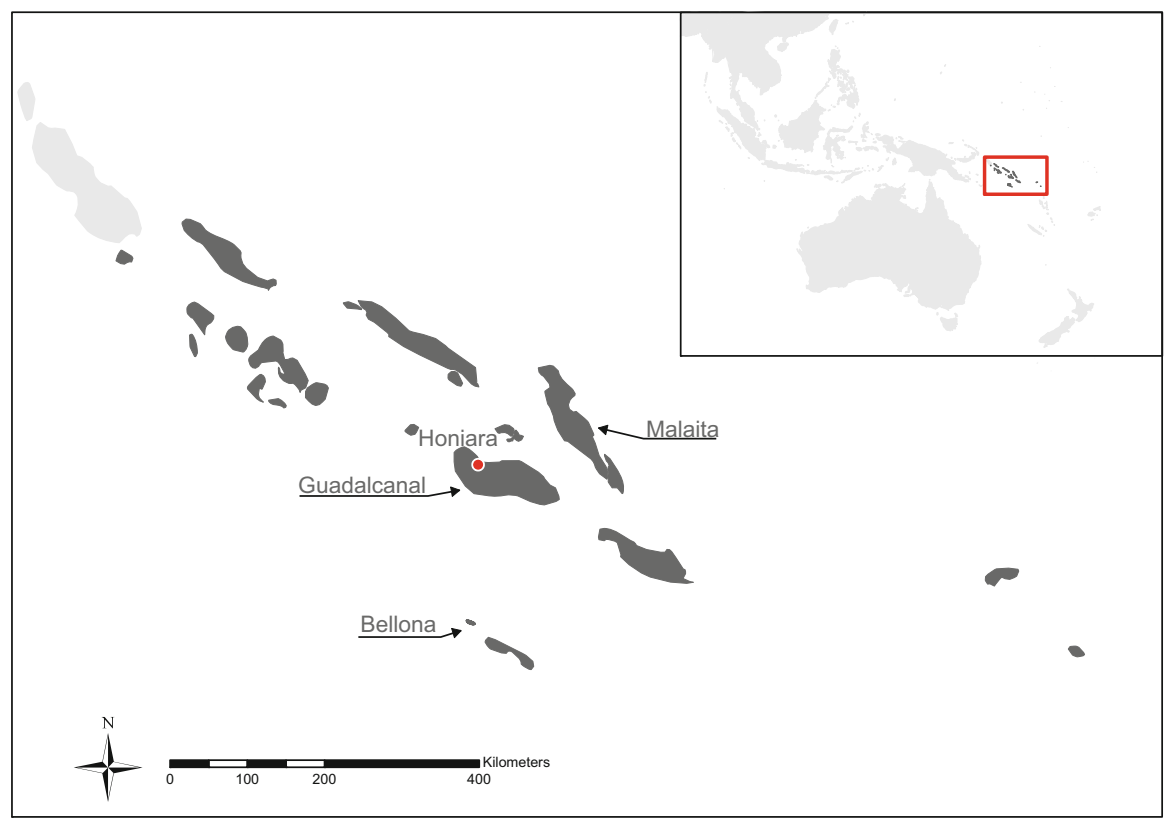

Fig. 4.1 Map of the study site-Bellona Island in the Solomon Islands. (Source: Reenberg et al. 2008)

during three fieldwork periods on Bellona: a pilot study in September 2006, a major fieldwork period from early November to late December 2006 and follow-up fieldwork in January-March 2007.

The object of our study is Bellona Island, which is part of RenBel (Rennell and Bellona), the smallest of the nine provinces of the Solomon Islands (Fig. 4.1). Bellona lies between $11^{\circ}$ and $12^{\circ}$ south, approximately $180 \mathrm{~km}$ south of Guadalcanal, where the national capital Honiara is located.

The island is an uplifted coral atoll of $16.23 \mathrm{~km}^{2}$, with steep cliffs towards the sea surrounding a more fertile plain in the centre of the island, which is the former lagoon floor and has locally high levels of phosphoric content. Due to the morphology of the island and numerous rock outcrops, only around one third of the island is considered suitable arable land (Breuning-Madsen et al. 2010).

The climate is tropical, with $3,000-4,000 \mathrm{~mm}$ of rainfall per year. Due to low water retention of the soils and the lack of access to surface water, less wet periods (May-August) may result in severe water shortage and stress. Frequent and intense cyclones also have a major impact on the environment and economy of Bellona in periods.

The inhabitants of the island, the Bellonese, are descendants of Polynesian migrants who arrived from Wallis Island (approx. $2500 \mathrm{~km}$ east of Bellona); in this respect, they belong to an ethnic minority in an otherwise primarily Melanesian society (Christiansen 1975). The total population is 2080 (in 2007), but the number of people actually present varies considerably over the course of the year due to 
the well-established tradition of seasonal migration to other parts of the Solomon Islands or abroad. The island is divided into three administrative districts: Sa' aiho $\left(2.56 \mathrm{~km}^{2}\right)$, Ghongau $\left(10.34 \mathrm{~km}^{2}\right)$ and Matangi $\left(3.33 \mathrm{~km}^{2}\right)$.

Agriculture is a prominent element in the livelihood portfolio. Subsistence production based on a shifting cultivation system supplemented by fishing has traditionally been the livelihood of the Bellonese. However, since first being described in the mid1960s (Christiansen 1975), the livelihoods of the Bellonese have included an array of non-subsistence activities such as copra production, short-to medium-term labour migration, government employment and external economic support (remittances) from kin living and working away from the island (mostly in Honiara) (Reenberg et al. 2008).

We will, in the following, specifically focus on how this significant change in some of the major conditions for the local livelihood in general, and the island's agriculture in particular, has influenced the land use transformation on Bellona Island in the course of the last 50 years. The present case will illustrate that the link between agriculture and rural development may not be as close as otherwise often perceived.

\subsection{Our Theoretical and Conceptual Lenses}

\subsubsection{Agricultural Intensification and Innovation}

Land use practices are known to be closely linked to societal institutions and the population (Turner et al. 2007). The theoretical scholarship on the population-agricultural change nexus has notably been anchored in two seminal works. One is Thomas Malthus's (1798) essay on the intrinsic imbalance between population growth rates and food production. The other is the book by Ester Boserup (1965) that suggests that farmers in "primitive" agricultural systems such as shifting cultivation tend to produce below the maximum because this allows for the optimal input-output efficiency. The conceptual frameworks suggested by Malthus and Boserup have had a huge impact on various scholars who have addressed the issue of how and why agricultural change and land use intensification occur. Although the models are contestable simplifications of real world situations, they have nevertheless provided a constructive starting point from which to discuss the complexity of agricultural change and land use trajectories. A number of classic studies (e.g. Adams and Mortimore 1997; Netting 1993; Turner et al. 1977, 1993; Wiggins 1995) have provided empirical documentation, which supports the perception that Boserup's model fits fairly well for land use systems that rely on land and labour extensive methods when land is abundant. More recent research emphasizes a number of economic, social or political factors that shape land use change beyond what is implicitly assumed in Boserup's simple model (Brookfield 2001; Stone 2001). One crucial issue is that the assumption of a direct, inverse relationship between efficiency and production concentration may not mirror realities (Stone 2001). The possible effect of local input-output energetic and population factors may be overshadowed by other factors; market access may, for example, play a significant role in the change trajectories when the land use system becomes part of a larger, spatial setting (Netting 1993). 
Social factors may also become important because agricultural production efficiency can vary culturally or because the demand for agricultural products is culturally determined. Political ecologists, like Blaikie and Brookfield (1987), specifically note that the Boserup model does not take into account the variation in farmers' ability to intensify agriculture as they wish. They stress that even under seemingly similar ecological and socio-economic conditions, population pressure may prompt very different patterns of agricultural change because of differences in farmers' ability to invest, withstand risk and attract subsidies. Hence, they see innovation and opportunity as crucial explanatory factors (Brookfield 2001, p. 189) that can lead to greater land-use intensity without increased labour input. Only in cases where no feasible innovations are available does it become necessary to employ more labour intensive strategies to meet the greater demands of an increasing population. Implementing the "sociometabolic regime" theory Fischer-Kowalski et al. (2011) document how the transition from a pre-industrial agrarian mode of production to a fossil-fuelled intensive system lowered labour time, but increased the pressure on environment. In other words, pathways to intensification in agriculture may need to be seen as more complex, diverse and unpredictable and not necessarily closely related to population change as suggested by Boserup.

A recent attempt to provide a more generic insight into the intensification of agricultural land use in the tropics is provided by Keys and McConnell (2005), who synthesize the findings of a large number of previously published case studies of intensification of agricultural land use in the tropics. The changes in the agricultural system were assessed with regard to the correspondence with biophysical variables as well as a large number of socioeconomic variables. Keys and McConnell (2005) noted, among a range of other conclusions, that a large number of cases did not experience any intensification, which also serves as a reminder that the path to increased inputs and outputs is not a given.

Hence, there is substantive support for the view that population pressure does not work in an unmediated fashion. There is an obvious need to look at the contemporary influence of globalization when discussing human ecology and development. The internal demographic growth becomes part of a larger picture that encompasses seasonal, generational and permanent flows of labour and consumers, as well as of knowledge, skills and priorities of immigrants and return migrants.

In the context of small isolated entities, like the island states that we will use as a case below, the theoretical reflections are taken a step further. Malm (2007), for example, urges researchers to look at the wider relationship to the modern world system when discussing human ecology and development, because society is not synonymous with people living in a certain place. Globalization has had at least two important consequences for local livelihoods. On the one hand, people have been affected by the global flow of ideas, money and commodities. On the other hand, remote societies are increasingly entering into "transnational corporations of kin" (Bertram and Watters 1985) as they include a diaspora of relatives who live and work outside the region but who still to a large extent provide emotional and financial support. 


\subsubsection{A Diagrammatic Heuristic}

In the later years of her scientific career, Boserup (1996) proposed in a brief paper a heuristic framework for a concise interpretation of contending theories of development and for a description of a variety of development processes related to the use of land resources. She proposes considering six structures that have a certain stability, but are subject to change if they are exposed to persistent pressure: environment, population, technology level, occupational structure, family structure, and culture. She sketches the structures as points on a circle, with arrows between any two structures to indicate the origin and direction of pressure one structure may exert on another. The framework was meant as a useful tool to describe the dynamic found in micro studies on the village level as well as to distinguish among the major conceptual approaches in development theory.

First, Boserup uses the heuristic to illustrate how the classical theories of Adam Smith, Malthus, Ricardo, Marx, Max Weber and Neo-Malthusians have different assumptions about the relationships between the structures, although four of them have population growth as a starting point for the process they discuss.

More importantly in the current context, she also suggests the heuristic as a useful lens in development theory when focusing on long-term population change and the interaction of the structures. Building on her works on Population and Technological Change and The Conditions of Agricultural Growth, she presents six models that are seen as sequential, representing what is usually considered the major stages in the development process of agricultural systems (Fig. 4.2). The stage and traits that are specifically relevant to explore in the current context are depicted in the "autonomous village", the independent territory. The diagram depicts the expected pathway of change in this stage. First, population increases beyond the level that can be supported by long-fallow methods $(\mathrm{P}=>\mathrm{E})$. Then, in step with the population increase, the cultivation changes to shorter fallow methods $(\mathrm{P}=>\mathrm{T})$. Landscape becomes specialized between fields, pasture and forest $(\mathrm{T}=>\mathrm{E})$. Occupational specialization increases, partly because the market becomes large enough to allow for specialized village crafts $(\mathrm{E}=>\mathrm{O})$. An increasing proportion of youths are trained outside agriculture $(\mathrm{O}=>\mathrm{F})$. Occupational differences in the village may develop into a caste system, resulting in segregated quarters of living in the village for different occupational groups $(\mathrm{O}=>\mathrm{C})$. Obviously, Boserup presents this with the caveat that in real life, interventions from outside or resistant structures often prevent this process of adaptation. However, the representational technique is believed to be useful to compare micro studies with results from macro studies from other disciplines and to foster interdisciplinary understanding.

\subsection{Land Use and Population Change on Bellona}

Land use and population development on Bellona Island from 1966 to 2006 have been subject to a detailed exploration (cf. Birch-Thomsen et al. 2010; Christiansen 1975; Reenberg et al. 2008). A combination of on-site registration, aerial photos, 
1 From hunting and gathering to crop production

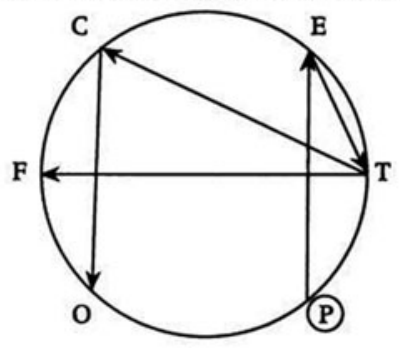

3 Pastoralists and nobility in the Eastern Hemisphere

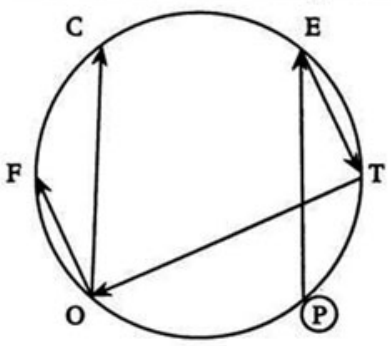

5 Industrialization in Western Europe

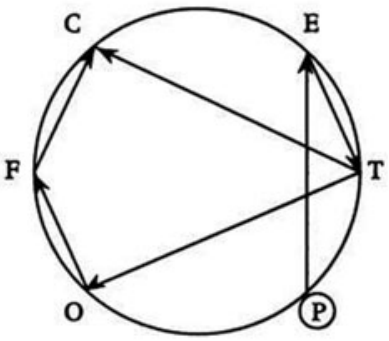

2 The autonomous village

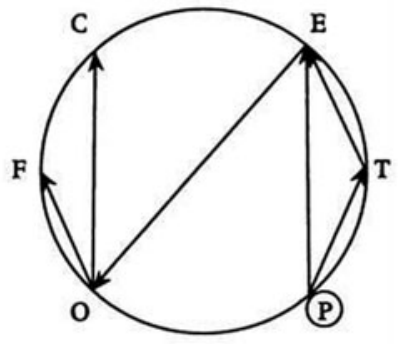

4 The process of urbanization

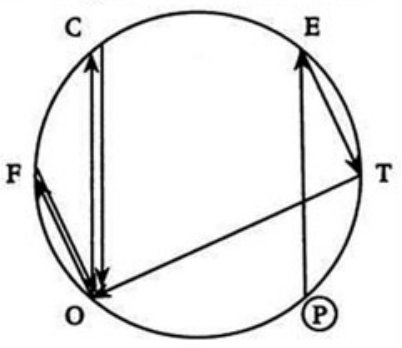

6 Fertility decline and cultural change in Western Europe

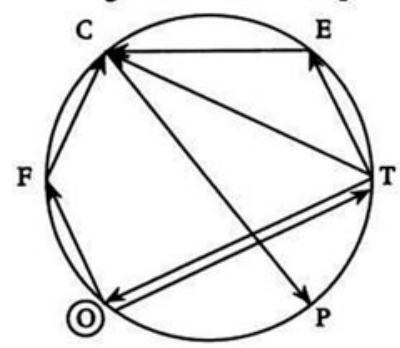

\section{$\mathrm{E}=$ Environment $\quad \mathrm{P}=$ Population $\quad \mathrm{T}=$ Technology level $\mathrm{O}=$ Occupational structure $\mathrm{F}=$ Family structure $\mathrm{C}=$ Culture}

Fig. 4.2 Analytical frameworks in selected models of the development process. The figure was originally presented in Boserup (1996, p. 510). It focuses on cases in which population change is accompanied by development. The six models should be seen as sequential, one beginning where the previous one ends, permitting population increase to continue because the structures are adaptable. (Source: Boserup 1996)

satellite images, household surveys and group interviews was employed to provide the needed insight into the dynamic development of Bellona's land use, population and livelihood system over the past 40 years. This information enables us to take a closer look at the co-evolution of population pressure and agricultural land use in the confined space of the island, which in Boserup's perspective would resample the "autonomous village" stage. 
Table 4.1 Population data 1966 and 2006, Bellona Island

\begin{tabular}{lccl}
\hline Population & 'De jure' & 'De facto' & Population density pers $/ \mathrm{km}^{2}$ (de facto $)^{\mathrm{c}}$ \\
\hline $1966^{\mathrm{a}}$ & 780 & 570 & $\sim 35$ \\
$2007^{\mathrm{b}}$ & 2,080 & 861 & $\sim 53$ \\
Population increase & $167 \%$ & $51 \%$ & \\
\hline
\end{tabular}

${ }^{a}$ Christiansen, 1975

${ }^{\mathrm{b}}$ CLIP census conducted on Bellona Island in January/February 2007

c Total area: $16.23 \mathrm{~km}^{2}$

Two sets of remotely sensed data were used to construct the historic and contemporary land use maps and to analyse land use changes within the study area from the mid-1960s to 2006: aerial photography from August 1966 and a Quickbird satellite image from October 2006.

In-depth group interviews with senior key informants were used to identify main drivers of change from the mid-1960s to 2006 and specifically people's perception of these changes. The population data was carefully selected through a census conducted in January-March 2007 in which all household members were recorded in detail, enabling a differentiation between permanent inhabitants and absentees as a result of the dynamic pattern of permanent and temporary migration.

Below sections 4.3.1 and 4.3.2 present results related to development in population and land use. Whereas the last section (4.3.3) views the results through a theoretical lens.

\subsubsection{Changing Population Pressure}

Christiansen's (1975) detailed study from the 1960s provides, together with the census conducted in 2007 , a unique opportunity to trace the changes in population pressure on the island (Table 4.1). Obviously, two snapshots in time tell us little about the entire transition process but they do provide some indication of the gross direction of change. If the total (de jure) population is taken into account, the annual growth rate is $2.4 \%$, a figure which corresponds reasonably well with that reported by Bourke et al. (2006) for the RenBel Province between 1986 and 1999 (2.2\%). It also indicates that the population growth rate has not changed significantly from the estimates for the period 1938-66 (2.1\% estimated by Christiansen (1975)). However, if the population present on the island (de facto) only is taken into account, the annual growth rates for the periods 1938-66 and 1966-2007 are 0.9 and 1\% respectively. This differential is explained by the very high mobility of the population, in particular of the youths. In the 1950s people started seeking job opportunities away from the island, for example in plantations on Guadalcanal or elsewhere in the Solomon Islands. This pursuit of other livelihoods (including educational opportunities) off the island has increased in importance up till today.

Even with the relatively low annual growth rate in the de facto population on the island there has been a pronounced increase in the overall population density (Table 4.1), yet with significant local variation between the three administrative districts (ranging from 76 pers $/ \mathrm{km}^{2}$ in Sa' aiho District to 36 pers $/ \mathrm{km}^{2}$ in Matangi District). 


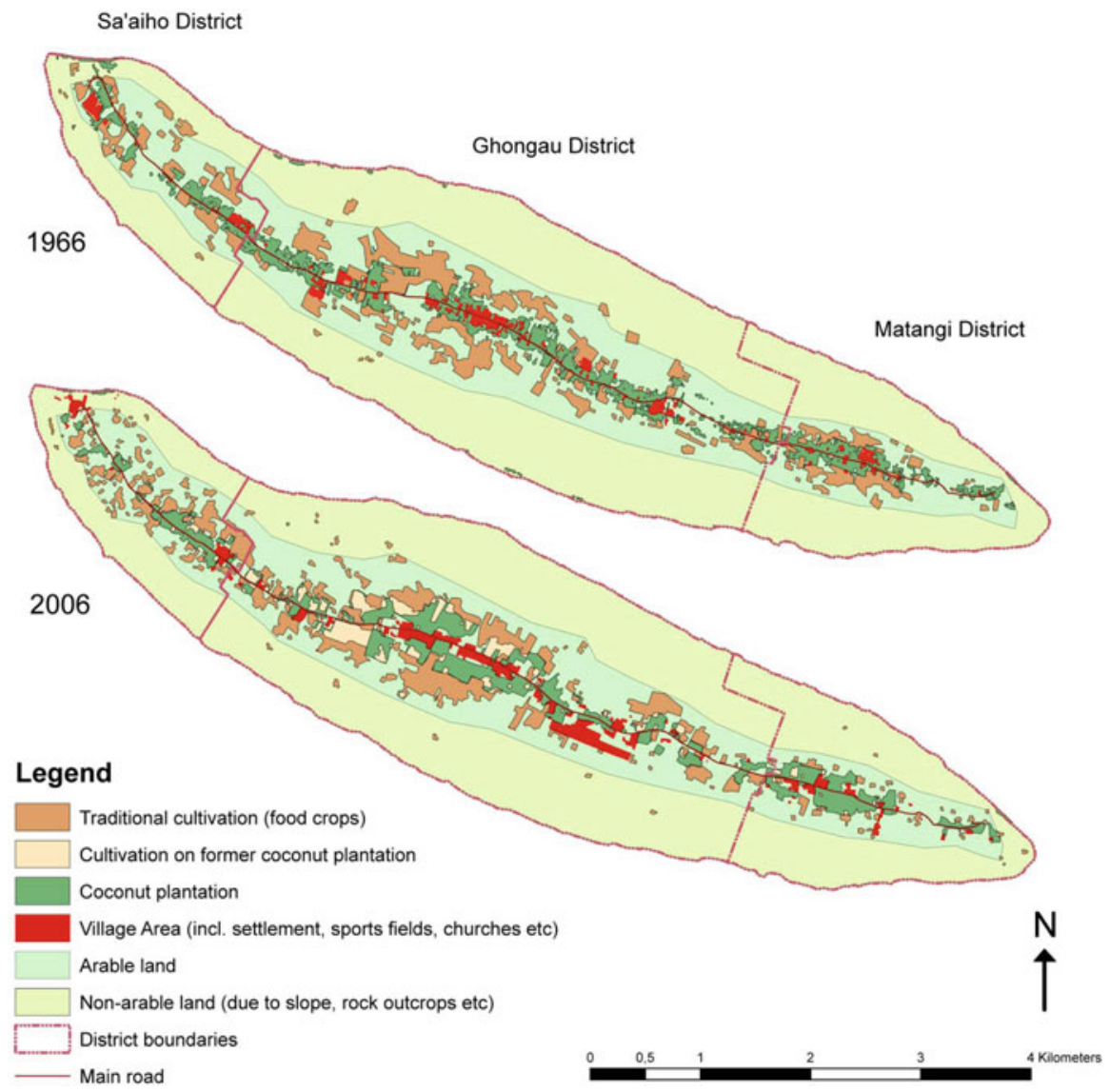

Fig. 4.3 Comparing land use/cover classes on Bellona in 1966 and 2006, derived from contemporary aerial photographs and Christiansen (1975), and compiled from a Quickbird satellite image and ground truth observations. (Source: 1966, Aerial photographs and Christiansen 1975; 2006, Quickbird satellite image and ground truth observations Birch-Thomsen et al. 2010)

\subsubsection{Land Use Dynamics}

In order to compare changes in land use between 1966 and 2006, Birch-Thomsen et al. (2010) have classified remotely sensed data into six distinguishable classes (Fig. 4.3). They are able to distinguish between four types of land use: (1) traditional cultivation (land identified to be within a cultivation cycle); (2) cultivation on former coconut plantations, where clearing or thinning of coconut palms has made room for food crop cultivation; (3) coconut plantations comprising dense clusters of coconut palms; and (4) the village area, including areas used for cultural (including sports) and religious activities (churches and burial grounds) and the airstrip. In addition, two classes are indicated: (5) the area suitable for cultivation (approximately $700 \mathrm{ha}$ ), estimated on the basis of the observed location of cultivation in both 1966 and 2006 as well as the general topography of the island); and (6) non-arable land, i.e. the rest of the island, covered with secondary and primary forest. 
Table 4.2 Changes in land use between 1966 and 2006

\begin{tabular}{|c|c|c|c|c|}
\hline \multicolumn{2}{|l|}{ Change in land use } & \multirow{2}{*}{$\begin{array}{l}1966\left(\mathrm{~km}^{2}\right) \\
1.67\end{array}$} & \multirow{2}{*}{$\begin{array}{l}2006\left(\mathrm{~km}^{2}\right) \\
1.38\end{array}$} & \multirow{2}{*}{$\frac{\text { Change }(\%)}{2}$} \\
\hline Food crops $\left(\mathrm{km}^{2}\right)$ & Traditional cultivation & & & \\
\hline & $\begin{array}{l}\text { Cultivation on former } \\
\text { coconut plantation }\end{array}$ & & 0.33 & \\
\hline \multicolumn{2}{|c|}{ Coconut plantation $\left(\mathrm{km}^{2}\right)$} & 1.23 & 1.07 & -13 \\
\hline \multicolumn{2}{|c|}{ Total land cultivated $\left(\mathrm{km}^{2}\right)$} & 2.90 & 2.78 & -4 \\
\hline \multicolumn{2}{|c|}{ Village area $\left(\mathrm{km}^{2}\right)$} & 0.19 & 0.39 & +105 \\
\hline \multicolumn{2}{|c|}{ Food crop area (ha) per pers. } & 0.29 & 0.20 & -31 \\
\hline
\end{tabular}

The land use history of Bellona from the late 1960s to the present day can be described in brief as follows. The agricultural land use in 1966 was dominated by garden-type food crop cultivation and dense plantations of coconut palms. The cultivation of food crops was, with few exceptions, dispersed/scattered within the zone of arable land, whereas coconut plantations were located close to the main east-west path on the island. The garden cultivation was dominated by vegetative propagated annuals laid or planted in small plots, which had been partly cleared after 3-15 years of fallow-though areas fallowed for longer than 5-6 years were already at this point in time reported to be increasingly rare (Christiansen 1975, p. 93). The traditional shifting cultivation system on Bellona depended on the use of intercropping or mixed cropping with a multitude of cultivated plants utilizing the different types of niches, yet gardens were often distinguished by the dominant plant (such as yam gardens, taro gardens, banana gardens or sweet potato gardens). Already in 1966 it was noted that the cultivation of sweet potato had become more common in response to the population increase as well as the expansion of coconut plantations, mainly because it can be grown after shorter fallow periods and it is less labour demanding than other food crops. The traditional shifting cultivation agriculture required a substantial labour input in its different phases, such as: clearing gardens (using bush knives and axes), burning the dried plant material, digging gardens using sticks to prepare the seedbed, planting by digging in the seed tubers, weeding two or three times (or more) and, finally, harvesting, which often takes place over an extended period of time in order to allow tubers to develop properly. Yam gardens were, however, seen as important in the mid-1960s, notably in terms of cultural identity, status and prestige (Christiansen 1975).

Coconut palms became important during the 1950s and these plots continued to grow in importance through the 1960s. The production, transport and marketing of copra were promoted by a cooperative society, mainly initiated by returning labourers from plantations elsewhere in the Solomons.

Given the extent of the population increase between 1966 and 2006, the corresponding change in land use, as indicated in Fig. 4.3, was surprisingly small (see Table 4.2). Despite a high degree of similarity, some overall changes can be noted. First, although the total land used for food production was basically constant, there was a decline of 29 ha under traditional cultivation. This land use class was still dispersed and mainly confined to the area of arable land, but there was a tendency for an increased number of small isolated plots within the area classified as non-arable 
land. A new class-cultivation within former coconut plantations-constituted almost one fifth of the total area for food crop production in 2006. Second, there was a reduction in the area with coconut plantations. The production of copra for export continued until the mid-1980s when it was stopped, partly due to poor marketing prospects and partly because many palms were damaged by Cyclone Namu in 1986 (Reenberg et al. 2008). Third, the village area more than doubled. In addition to an increased number of homesteads, sports facilities (football and rugby fields and basketball courts) and an airstrip take up a considerable share of the arable land.

The traditional practice of shifting cultivation continued to be employed, yet yam and taro declined in importance whereas short fallow and permanent gardens with sweet potato gained prominence. The number of plots with previously very minor or new crops such as maize, cassava and watermelon also increased.

In addition to the land use data presented in Fig. 4.3- the two "snapshots in time"-we have tried to reconstruct the land use prior to and between them on the basis of interviews with senior members of the community (as illustrated in Fig. 4.4). Although little change was observed between 1966 and 2006, it is understood that the temporal variation in land use followed a change path along which the "coconut area" expanded at the cost of "food crop area" in the 1970-80s due to favourable prices at the market-followed by a decline in the 1990-2000s. The more recent cultivation of former coconut plantations indicates a further reduction of this class in the future.

The general trend in the importance of different types of crops corresponds well with reported changes in food preferences on the island (Reenberg et al. 2008). Of the traditional staples, less than half of the sampled households eat yam daily, only one third have taro daily or weekly, and one third never eat taro. In contrast, all households eat sweet potatoes either daily ( $79 \%$ ) or weekly ( $21 \%)$. The changes in food preference are reflected in a concomitant reduction by almost one third in the food producing area per person living on the island between from 1966 and 2006.

Not only the temporal but also the spatial variations between districts are significant. In the case of Sa'aiho District (towards the north-west), very little or no change has occurred in the total amount of land under cultivation, whereas a reduction of close to a quarter has taken place in Matangi District (towards the south-east). While the area for food crop production in Sa'aiho increased by $12 \%$ from 1966 to 2006, this was almost counterbalanced by the decreasing importance of coconut plantations - many households still rely on traditional food production (see Textbox 1). In contrast, in Matangi the food crop area was reduced by almost $60 \%$ while that of coconut plantations increased slightly. There are three possible explanations for this variation. First, because Matangi District has had the lowest population increase and density, the demand for cropland has been lower. Second, unlike in other parts of the island, the majority of the land in Matangi belongs to a few families, of which one has had few sons for several generations; consequently, land has been concentrated in a few hands, allowing for a continued long fallow cycle. Third, as illustrated by a very low food crop area per person ( $0.08 \mathrm{ha}$ ) and the fact that only minor changes have occurred in the agricultural system, people in Matangi District are less dependent on agriculture for their livelihoods (see Textbox 2). The spatial variation in the observed land use trajectories are mainly explained through institutional factors, of 


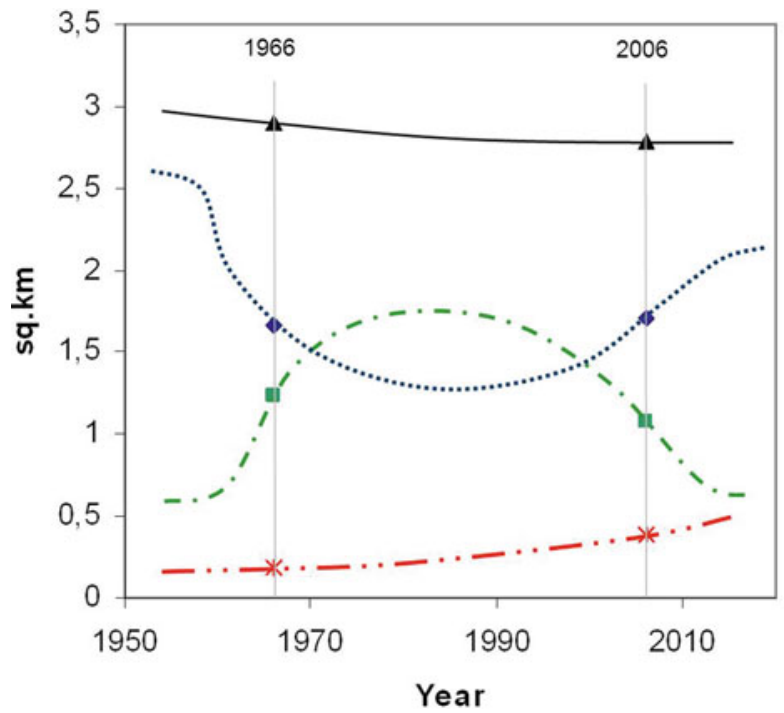

\ Total area cultivated - Foodcrop area - Coconut area * Village area

Fig. 4.4 Hypothesized development in land use based on observations (1966 and 2006) and interviews with the Bellonese in 2006- "foodcrop area" includes both traditional cultivated area and cultivation of former coconut areas

which differences in access to land as well as access to the "new" alternative livelihood options (e.g. migration, seasonal mobility and remittances) play an important role.

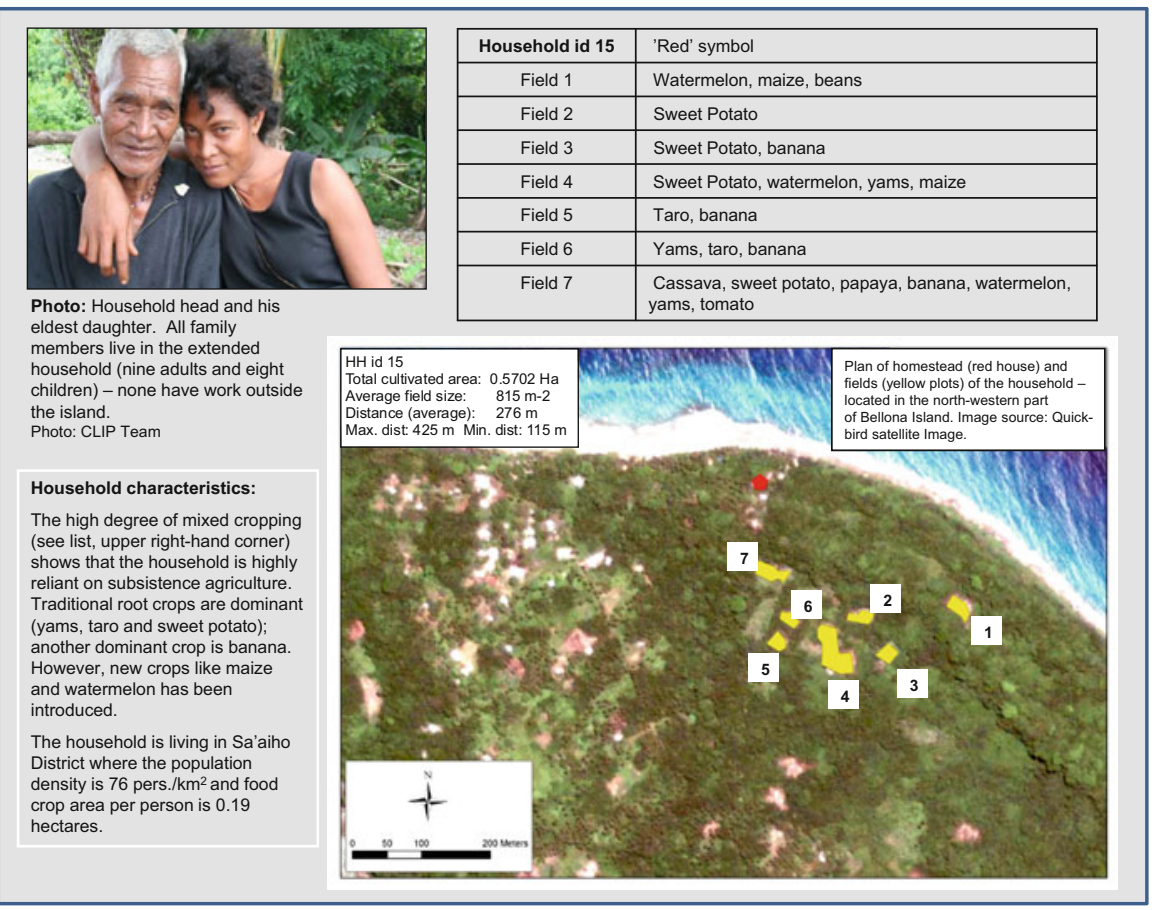

Textbox 1 


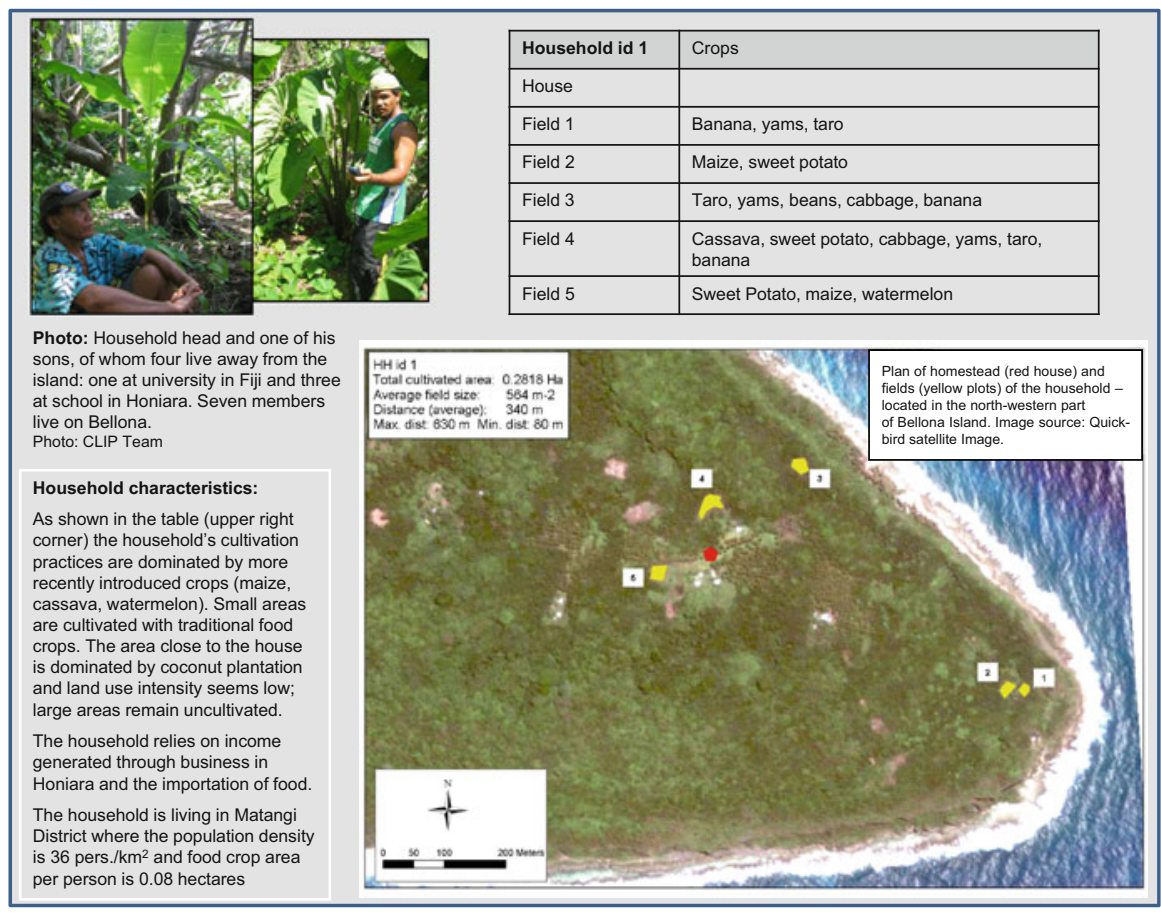

Textbox 2

\subsubsection{Land use change seen through a theoretical lens}

The "grand theories" of agricultural intensification anticipated that the outcome of the population increase would either be decreased productivity due to land shortage, with a possible future collapse of the system (Malthusian path), or increased productivity through intensified land use and innovations (the "Boserupian path"; Stone 2001).

Based on the above analysis it is clear that none of these "grand theories" can fully explain what has been experienced on Bellona Island - not at the "island scale" and even less so at the "household scale". Making use of the holistic understanding of livelihoods, and the assumption that people pursue a range of livelihood outcomes by drawing on a range of assets to pursue a variety of activities (Farrington et al. 1999) may help us understand the complexity and diversity in response to drivers of change. In their reflections on the development within livelihood research, de Haan and Zoomers (2005) advocate the analytical and methodological use of the concept "pathways" to describe patterns of livelihood among particular social groups. Several more general livelihood pathways may be identified on the basis of different access to and availability of assets for the household. One such pathway is shown in Fig. 4.5.

A common response among the Belonese to the increase in population with the given limited agricultural potential of the island has been, at an early stage, to relocate part of the family to the capital Honiara, thereby creating a "multi-locational" 


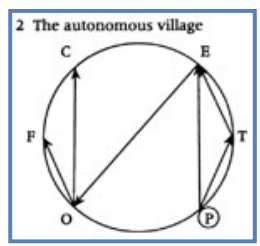

(From Boserup 1996)
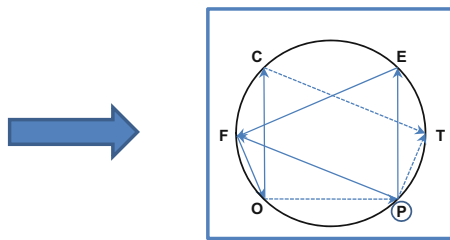

(Bellona 2006)

Response to population increase $(P)$ and limited agricultural potential $(E)$

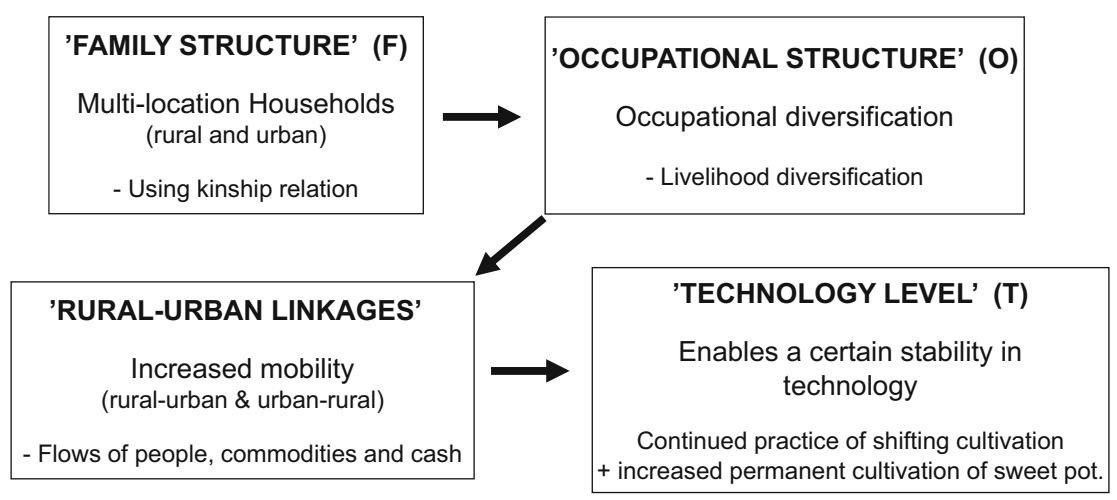

Fig. 4.5 A possible livelihood pathway on Bellona Island; inspired by Boserup's model (1996) for an analytical framework

household, which can make use of kinship relations in both the "rural" (on the island) and the "urban" livelihood opportunities. This increases access to a variety of livelihood options, and eventually leads to occupational diversification. To sustain the large number of options both spheres (rural and urban) must be maintained through increased mobility of people, goods and money, which strengthen the rural-urban linkages. Through occupational diversification and rural-urban linkages it has been possible to find alternative support systems (through the market) to take the place of agriculture as the main food supplier and thereby to "conserve" the culturally important land use practices despite a more than $50 \%$ increase in population between 1966 to 2006. Furthermore, it has made it possible to maintain the traditional agricultural "shifting cultivation" with no or very few technological changes. Thus, although the pathway of change observed on Bellona initially may have some overlap with Boserup's model of development in "the autonomous village" (see Fig. 4.5), it is clear that present day connectedness calls for more complex analytical frameworks in order to understand the coupled human-environment system. Recent attempts to include the increased global connectedness have been presented in various advancements of the conceptualization of land teleconnections (Haberl et al. 2009; Seto et al. 2012). 


\subsection{Conclusion}

While the land use system on Bellona may be seen to examplify a "close to autonomous village situation" in the Boserupian heurisitc rhetoric because of its immediate appearance as a traditional shifting cultivation system, the island specific population-land use nexus and the classical Boserupean trajectory of intensification have been bypassed.

The apparent status quo situation of the land use strategies can be explained by the important cultural value embedded in the traditional agricultural practices. Overall, the area under cultivation in Bellona since 1966 has remained remarkably unchanged despite the significantly increasing population. The land use pattern has also remained fairly constant although a few new crops have emerged in "waves of change" (e.g. coconut palms making way for more permanent gardens of mainly sweet potato and/or watermelon). The production techniques as well as technology have remained unchanged as a traditional shifting cultivation system in the absence of affordable inputs such as agro-chemical fertilizer for more intensive practices, in spite of the fact that the population pressure has grown considerably.

Changes in economic and human resources in Bellona have, however, also made living conditions and food provision challenges very different, mainly as a result of income opportunities occurring from migration, remittances, aid and increasing bureaucracy. Faced with scarce land resources and opportunities found off the island, the Bellonese have under the new circumstances been able to generate alternative livelihoods to subsistence agriculture, for example, through the mobility of family members.

The value the Bellonese give to tradition and culture is another important part of the explanation of the land use stability. Many inhabitants consider traditional agriculture to be an important part of their daily life, beyond rational assessment criteria. Yam gardens are, for example, attributed great importance for cultural identity; they help maintain the social institutions that continue to provide an important social safety net (embedded in various collective labour relations and the sharing of harvests among kin). Alongside the seeming continuation or status quo of the land use pattern, a number of changes have occurred, some closely linked to human-land relations and others to changes in socioeconomic conditions. Notably, the food producing area per person in 2006 has decreased by one third compared to 1966. Apparently the influence of the "modern way of life", particularly on young migrants returning after completing their education or (un)successfully pursuing job opportunities has reduced the inclination for "hard work" in the traditional gardens among the younger generations. Within the last decade, eight new shops have opened on the island, functioning as storage depots for imported foodstuffs and other goods. This indicates that people do have money to spend and that the availability of "modern" food on the island has increased. The overall portfolio of livelihood strategies observed has become much more diversified.

Although our study has shown clear signs of the developments suggested by classic scholarship on the population-agricultural change nexus, it also illustrates how land use practices are closely linked to societal institutions and their ability to adapt to changing socioeconomic conditions. Despite the pressures on land resources 
resulting from an increasing population, a high degree of continuity is evident in the traditional shifting cultivation system which, albeit decreased in extent, still plays an important cultural role for the identity of the Bellonese. The traditional cultivation system continues to be a significant component of the contemporary food provision, but as a supplement to the new portfolio of strategies, which supports the increasing number of people on the island.

Acknowledgments The paper has been inspired by the authors' interaction with the Global Land Project, a programme hosted by the University of Copenhagen and guided by the International Geosphere Biosphere Programme (IGBP) and the International Human Dimension Programme (IHDP). The field work was a component of the "Sustainable resource use or imminent collapse? Climate, livelihoods and production in the southwest Pacific" or CLIP project of the Galathea 3 expedition under the auspices of the Danish Expedition Foundation. This is Galathea 3 contribution no. 45. CLIP was carried out in collaboration between the University of Copenhagen, the Danish Meteorological Institute, the University of the South Pacific and the Solomon Islands Meteorological Service Centre. We are grateful to the Danish Expedition Foundation for accepting the project and for ensuring funding from the Bikuben Foundation and for funding provided by Knud Højgaards Foundation, COWIfonden, the Brødrene Hartmann Foundation, and the Department of Geography and Geology, University of Copenhagen. The authors also greatly appreciate the strong support from the government of Solomon Islands and are grateful for the collaboration with our research colleagues as well as the hospitality and invaluable assistance provided by the communities, local assistants and authorities of Bellona.

Open Access This chapter is distributed under the terms of the Creative Commons Attribution Noncommercial License, which permits any noncommercial use, distribution, and reproduction in any medium, provided the original author(s) and source are credited.

\section{References}

Adams, W. M., \& Mortimore, M. J. (1997). Agricultural intensification and flexibility in the Nigerian Sahel. The Geographical Journal, 163, 150-160.

Bertram, I. G., \& Watters, R. F. (1985). The MIRAB economy in South Pacific microstates. Pacific Viewpoint, 26, 497-519.

Birch-Thomsen, T., Reenberg, A., Mertz, O., \& Fog, B. (2010). Continuity and change: Spatiotemporal land use dynamics on a small island in SW-Pacific. Singapore Journal of Tropical Geography, 31, 27-40.

Blaikie, P., \& Brookfield, H. C. (1987). Land degradation and society. London: Methuen.

Boserup, E. (1965). The conditions of agricultural growth: The economics of agrarian change under population pressure. New York: Aldine.

Boserup, E. (1996). Development theory: An analytical framework and selected application. Population and Development Review, 22(3), 505-515.

Bourke, R. M. et al (2006). Solomon Islands smallholder agriculture study. Canberra: AusAID.

Breuning-Madsen, H., Bruun, T. B., \& Elberling, B. (2010). An indigenous soil classification system for Bellona Island-a raised atoll in the South Pacific Solomon Islands. Singapore Journal of Tropical Geography, 31, 85-99.

Brookfield, H. C. (2001). Intensification, and alternative approaches to agricultural change. Asia Pacific Viewpoint, 42, 181-192.

Christiansen, S. (1975). Subsistence on Bellona Island (Mungiki): A study of the cultural ecology of a Polynesian outlier in the British Solomon Islands protectorate. Copenhagen: C.A. Reitzels Forlag. 
De Haan, L., \& Zoomers, A. (2005). Exploring the frontier of livelihood research. Development and Change, 36, 27-47.

Farrington, J., Carney, D., Ashley, C., \& Turton, C. (1999). Sustainable livelihoods in practice: Early applications of concepts in rural areas. ODI Natural Resource Perspectives, 42. London: Overseas Development Institute (ODI).

Fischer-Kowalski, M., Singh, S. J., Lauk, C., Remesch, A., Ringhofer, L., \& Grünbühel, C. M. (2011). Sociometabolic transitions in subsistence communities: Boserup revisited in four comparative case studies. Human Ecology Review, 18, 147-158.

Fox, J., Rindfuss, R. R., Walsh, S. J., \& Mishra, V. (2003). People and the environment: Approaches for linking household and community surveys to remote sensing and GIS. London: Kluwer.

GLP (Global Land Project). (2005). Science plan and implementation strategy. IGBP Report No. 53/ IHDP Report No. 19. Stockholm: IGBP.

Haberl, H. et al (2006). From LTER to LTSER: Conceptualizing the socio-economic dimension of long-term socio-ecological research. Ecology and Society, 11, 13.

Haberl, H., Erb, K-H., Krausmann, F., Berecz, S., Ludwiczek, N., Martinez-Alier, J., Musel, A., \& Schaffartzik, A. (2009). Using embodied HANPP to analyze teleconnections in the global land system: Conceptual considerations. Geografisk Tidsskrift-Danish Journal of Geography 109(2), 119-130.

Keys, E., \& McConnell, W. J. (2005). Global change and the intensification of agriculture in the tropics. Global Environmental Change, 15, 320-337.

Lambin, E., \& Geist, H. J. (2006). Land-use and land-cover change: Local processes and global impacts. Berlin: Springer.

Malm, T. (2007). No island is an 'island': Some perspectives on human ecology and development in Oceania. In A. Hornborg \& C. Crumley (Eds.), The world system and the earth system: Global socioenvironmental change and sustainability since the Neolithic (pp. 268-279). Walnut Creek: The Left Coast Press.

Malthus, R. T. (1798). An essay on the principle of population. London: J. Johnson.

Netting, R. M. (1993). Smallholders, householders: Farm families and the ecology of intensive, sustainable agriculture. Palo Alto: Stanford University Press.

Reenberg, A., Birch-Thomsen, T., Mertz, O., Fog, B., \& Christiansen, S. (2008). Adaptation of human coping strategies in a small island society in the SW Pacific-fifty years of change in the coupled human-environment system on Bellona, Solomon Islands. Human Ecology, 36, 807-819.

Scoones, I. (1999). New ecology and the social sciences: What prospects for a fruitful engagement? Annual Review of Anthropology, 28, 479-507.

Seto, K. C. et al (2012). Teleconnections and sustainability: New conceptualizations of global urbanization and land change. Proceedings of the National Academy of Sciences of the United States of America, 109, 7687-7697.

Stone, G. D. (2001). Theory of the square chicken: Advances in agricultural intensification theory. Asia Pacific Viewpoint, 42, 163-180.

Turner, B. L., Hanham, R., \& Portararo, A. (1977). Population pressure and agricultural intensity. Annals of the Association of American Geographers, 67, 384-396.

Turner, B. L., Hyden, G., \& Kates, R. (Eds.). (1993). Population growth and agricultural change in Africa. Gainesville: University of Florida Press.

Turner, B. L., Lambin, E. F., \& Reenberg, A. (2007). The emergence of land change science for global environmental change and sustainability. Proceedings of the National Academy of Sciences of the United States of America, 104, 20666-20671.

Walker, B. H., Anderies, J. M., Kinzig, A. P., \& Ryan, P. (2006). Exploring the resilience in socialecological systems through comparative studies and theory development: Introduction to the special issue. Ecology and Society, 11, 12.

Wiggins, S. (1995). Change in African farming systems between the mid-1970s and the mid-1980s. Journal of International Development, 7, 807-848.

Zimmerer, K. S., \& Bassett, T. J. (2003). Political ecology-an integrative approach to geography and environment-development studies. New York: Guilford. 